\title{
Evaluasi Pola Operasi Waduk Tamblang di Kabupaten Buleleng, Provinsi Bali
}

\author{
Evaluation of Tamblang Reservoir Operation in Buleleng Regency, Bali \\ Province
}

\author{
Mawiti Infantri Yekti ${ }^{*}{ }^{*}$, Tjokorda Gde Raka Wijakesuma ${ }^{1}$, Kadek Diana Harmayani ${ }^{1}$ \\ ${ }^{1}$ Program Studi Sarjana Teknik Sipil, Fakultas Teknik, Universitas Udayana, Bali, Indonesia
}

\section{Article info:}

Kata kunci:

air baku, irigasi, inflow, outflow, simulasi waduk Tamblang

Keywords:

inflow, irrigation, outflow, raw water, simulation of Tamblang reservoir

Article history:

Received: 28-06-2020

Accepted: 28-11-2020

${ }^{*}$ Koresponden email: wiwiet91@unud.ac.id

\begin{abstract}
Abstrak
Bendungan Tamblang dibangun untuk memenuhi kebutuhan irigasi dan air baku di Kecamatan Sawan dan Kecamatan Kubutamban Kabupaten Buleleng. Waduk ini berada di aliran Sungai Tukad Daya dan direncanakan mempunyai total tampungan sebesar $6,137,228 \mathrm{~m}^{3}$ sedangkan tampungan waduk efektif sebesar 4,199,646 $\mathrm{m}^{3}$. Fungsi Waduk Tamblang adalah untuk irigasi sebesar 584 ha serta penyediaan air baku sebesar 306 liter/detik. Simulasi operasi Waduk Tamblang menggunakan alternatif debit andalan $80 \%$ dan $90 \%$. Data pendukung berupa data curah hujan harian, data debit permukaan aliran Sungai Tukad Daya dan data klimatologi dianalisis untuk mengetahui curah hujan andalan $\mathrm{R}_{50}$ dan $\mathrm{R}_{80}$, debit andalan, evapotranspirasi potensial, curah hujan efektif, kebutuhan air irigasi (KAI), serta kebutuhan air baku pada Kecamatan Sawan dan Kecamatan Kubutambahan. Operasi waduk disimulasikan ke dalam lima alternatif dengan keandalan inflow $\mathrm{Q}_{80}$ dan Q90. Hasil simulasi operasi Waduk Tamblang terjadi surplus pada simulasi alternatif 4 dan alternatif 5. Pola tanam alternatif 4 yaitu padijagung-kacang tanah dan alternatif 5 yaitu padi-buncis-bawang-kedelai dan ini sudah disesuaikan pada pola tanam eksisting. Hasil simulasi alternatif 4 dan 5 ini dapat memenuhi kebutuhan air baku dan air irigasi dengan persentase terlayani $100 \%$.
\end{abstract}

\begin{abstract}
One of dams to be built in North Bali to meet irrigation and raw water needs in Sawan District and Kubutamban District, Buleleng Regency is the Tamblang Dam. The reservoir is located in Tukad Daya river and built to have a total storage capacity of $6,137,228 \mathrm{~m}^{3}$ while the effective reservoir is 4,199,646 $\mathrm{m}^{3}$. The functions of Tamblang reservoir are used for irrigation of 584 ha and supply of raw water of $306 \mathrm{l} / \mathrm{sec}$. Tamblang reservoir operation simulation with $80 \%$ and $90 \%$ alternative discharge. Supporting data such as daily rainfall data, Tukad Daya discharge data, and climatological data for determining dependable rainfall of $R_{50}$ and $\mathrm{R}_{80}$, dependable discharge, potential evapotranspiration, effective rainfall, the need for irrigation water (KAI), then the demand for raw water in Sawan District and Kubutambahan. Reservoir operation is simulated in five alternatives with inflows $\mathrm{Q}_{80}$ and $\mathrm{Q}_{90}$. The results of Tamblang reservoir operation simulation in a surplus in simulation alternative 4 and 5 . The alternative cropping pattern 4 is rice-corn-peanut and alternative 5 is rice-beans-onion-soybean and this has been adjusted to existing cropping pattern. The simulation results of alternatives 4 and 5 can meet the needs of raw water and irrigation water with a percentage served $100 \%$.
\end{abstract}




\section{Pendahuluan}

Bendungan adalah konstruksi yang dibuat sedemikian rupa sebagai langkah untuk menampung laju air menjadi tampungan waduk, atau dalam fungsi sebagai tempat hiburan (Banihabib and Nazarieh 2019). Salah satu bendungan yang sedang dibangun di Bali Utara direncanakan akan melayani keperluan irigasi dan air baku di Kecamatan Sawan dan Kecamatan Kubutamban Kabupaten Buleleng adalah Bendungan Tamblang. Waduk Tamblang direncanakan mempunyai total tampungan sebesar $6,137,228 \mathrm{~m}^{3}$ sedangkan tampungan waduk efektif sebesar 4,199,646 $\mathrm{m}^{3}$ (Balai Wilayah Sungai Bali Penida 2018).

Waduk Tamblang direncanakan memberikan manfaat irigasi sebesar 584 ha serta penyediaan air baku sebesar 306 liter/detik. Waduk Tamblang berlokasi pada aliran Tukad Daya yang secara administratif berada di dua desa yaitu Desa Sawan dan Desa Bila Kecamatan Kubutambahan Kabupaten Buleleng. Sungai Tukad Daya memiliki daerah aliran sungai sebesar $78.63 \mathrm{Km}^{2}$ dan memiliki hulu pada jalur pematang pegunungan, yaitu pada lereng utara dari kaldera Buyung - Baratan dan lereng kaldera Batur dengan elevasi wilayah 1,125-16,000 m dpl, mengalir ke arah utara sepanjang kurang lebih $40 \mathrm{~km}$ dan bermuara di Laut Bali (Balai Wilayah Sungai Bali Penida 2018).

Simulasi operasi waduk dalam pembangunan bendungan merupakan hal penting untuk dilakukan agar nantinya waduk memiliki pola operasi waduk standar dalam pemenuhan irigasi dan air baku (Chen et al. 2020; Liu and Xia 2004). Simulasi operasi waduk menggunakan beberapa alternatif keandalan inflow $\mathrm{Q}_{80}$ dan $\mathrm{Q}_{90}$ dan alternatif pemberian air irigasi dengan variasi pola tata tanam serta kebutuhan air baku dianalisis ulang berdasarkan data terbaru dan analisis proyeksi kebutuhan air baku. Tujuan dari penelitian ini adalah untuk mengetahui pola operasi pada Waduk Tamblang untuk pemenuhan air baku dan irigasi.

\section{Bahan dan Metode}

\subsection{Waduk, fungsi dan ketersediaan air}

Waduk didefinisikan sebagai tampungan buatan yang tercipta dari akibat dibuatnya suatu bendungan. Dijelaskan bahwa definisi bendungan adalah bangunan yang berbentuk timbunan tanah, timbunan batu, beton, dan/atau pasangan batu yang dibuat sedemikian rupa selain untuk menahan dan menampung limbah tambang (tailing) atau menampung lumpur sehingga terciptanya waduk (Peraturan Pemerintah Republik Indonesia 2010). Fungsi utama waduk yaitu untuk menadah air pada saat debit air tinggi dan digunakan saat debit air rendah. Untuk fungsi-fungsi lainnya yaitu, memberikan lokasi untuk budidaya perikanan, sumber air irigasi, pengendali banjir, menyediakan air bersih bagi penduduk dan sebagai penyumbang aliran air. Kapasitas dari waduk yang dibutuhkan untuk memenuhi kebutuhan tertentu adalah tergantung pada faktor variabilitas aliran sungai, besarnya permintaan kebutuhan dan tingkat keandalan waduk.

Ketersediaan air adalah jumlah air atau debit air yang diprediksi secara konstan ada di sebuah lokasi (bendung atau bangunan air lainnya) di sungai dengan jumlah tertentu dan dalam periode tertentu (Direktorat Irigasi 1980 dalam (Triatmodjo 2008)). Ketersediaan air pada waduk pada analisis ini terdapat dua indikator yang menentukan yaitu debit andalan aliran sungai dan curah hujan andalan pada daerah tangkapan sungai.

\subsection{Debit andalan aliran sungai}

Debit andalan (dependable flow) merupakan debit minimum sungai dalam jangka waktu tertentu untuk dapat memenuhi berbagai macam keperluan. Jika ditetapkan debit andalan sebesar $80 \%$ berarti akan ditemui resiko debit yang lebih kecil dari debit andalan yaitu sebesar $20 \%$ dari data pengamatan (Yaghmaei et al. 2018). Untuk keperluan irigasi biasanya menggunakan probabilitas $80 \%$, untuk kebutuhan air minum dan industri diperlukan probabilitas keandalan lebih besar yaitu sebesar $90 \%$ sampai dengan 95\% dengan terpenuhi debit minimum 10\% sampai 5\%. Perhitungan debit andalan DAS Tukad Daya menggunakan metode Weibull untuk mencari keandalan $90 \%\left(\mathrm{Q}_{90}\right)$ dan keandalan 80\% (Q80). Rumus Weibull sebagai berikut (Yekti et al. 2017):

$$
P=\frac{m}{n+1} \times 100 \%
$$


dengan:

$\mathrm{P}=$ probabilitas metode Weibull

$\mathrm{n}=$ jumlah data

$\mathrm{m}=$ nomor urut data (data besar ke kecil)

\subsection{Curah hujan andalan}

Curah hujan andalan adalah intensitas curah hujan minimum yang masuk kedalam suatu daerah tangkapan dengan besaran tertentu yang mempunyai peluang terpenuhi yang dapat difungsikan untuk berbagai macam keperluan. Mengacu pada Kriteria Perencanaan Irigasi-01 (Kementrian Pekerjaan Umum 2003) di mana biasanya curah hujan andalan yang dicari yaitu keandalan 50\% $\left(\mathrm{R}_{50}\right)$ dan 80\% $\left(\mathrm{R}_{80}\right)$ untuk keperluan irigasi, serta keandalan 90\% ( $\left.\mathrm{R}_{90}\right)$ untuk keperluan air baku. Perhitungan curah hujan andalan pada Tukad Daya menggunakan metode Weibull untuk mencari keandalan 50\% $\left(\mathrm{R}_{50}\right)$, 80\% $\left(\mathrm{R}_{80}\right)$ dan 90\% $\left(\mathrm{R}_{90}\right)$. Persamaan metode Weibull sebagai berikut:

$$
P=\frac{m}{n+1} \times 100 \%
$$

dengan:

$\mathrm{P}=$ probabilitas metode Weibull

$\mathrm{n}=$ jumlah data

$\mathrm{m}=$ nomor urut data (data besar ke kecil)

\subsection{Kebutuhan air pada waduk}

Pemanfaatan air erat hubungannya dengan ketersediaan jenis pemanfaatan seperti pemanfaatan air yang difungsikan irigasi, perikanan, peternakan, industri, air baku dan lainnya. Konsep mengenai kebutuhan air perlu dimengerti secara baik agar pola penggunaan air dapat berjalan sesuai. Kebutuhan air pada analisis ini terdapat tiga indikator yang menentukan, yaitu kebutuhan air irigasi, air baku dan evaporasi (Kuswanto 2004).

\subsection{Kebutuhan air irigasi}

Sebagian besar kebutuhan air irigasi dapat terpenuhi dari air permukaan. Faktor-faktor yang mempengaruhi kebutuhan air irigasi adalah faktor klimatologi, kondisi tanah, koefisien tanaman, pola tanam, pasokan air, luar daerah irigasi, efisiensi irigasi, penggunaan kembali air drainase untuk irigasi, sistem golongan, jadwal tanam dan lain sebagainya menggunakan Pers. 3 (Adhiatma, Sayekti, and Prasetyorini 2014):

$$
\begin{aligned}
& G F R=E t c+P+I R+W L R \\
& N F R=G F R-R e \\
& D R=\frac{N F R}{I E}
\end{aligned}
$$

dengan:

$\mathrm{DR}=$ kebutuhan air irigasi (liter/detik/ha)

Etc $=$ kebutuhan air konsumtif $(\mathrm{mm} / \mathrm{hari})$

IR = kebutuhan air pengolahan $(\mathrm{mm} / \mathrm{hari})$

$\mathrm{WLR}=$ kebutuhan air mengganti lapisan air $(\mathrm{mm} /$ hari)

$\mathrm{P} \quad=\operatorname{perkolasi}(\mathrm{mm} / \mathrm{hari})$

$\operatorname{Re}=$ hujan efektif ( $\mathrm{mm} /$ hari)

$\mathrm{IE} \quad=$ efisiensi irigasi $(\%)$

GFR $=$ kebutuhan air total $(\mathrm{mm} /$ hari $)$

NFR $=$ kebutuhan air bersih di lahan ( $\mathrm{mm} /$ hari)

\subsection{Evapotranspirasi potensial}

Evapotranspirasi potensial didapatkan dengan menggunakan metode Penman Modifikasi oleh FAO. Besarnya evapotranspirasi potensial menggunakan rumus teoritis dan menggunakan 
faktor-faktor klimatologi setempat. Persamaan evapotranspirasi Penman Modifikasi adalah sebagai berikut (Mahendra et al. 2015):

$$
\text { Eto }=C(w \times R n+(1-w) \times f(u) \times(e a-e d))
$$

dengan:

Eto $=$ evapotranspirasi potensial $(\mathrm{mm} / \mathrm{hari})$

$\mathrm{C}=$ angka koreksi penman

$\mathrm{w}=$ faktor yang berhubungan dengan temperatur

$\mathrm{Rn}=$ lama penyinaran matahari $(\mathrm{mm} / \mathrm{hari})$

$\mathrm{f}(\mathrm{u})=$ fungsi kecepatan angin $(\mathrm{km} / \mathrm{hari})$

ea $=$ tekanan uap jenuh (mbar)

ed $=$ tekanan uap nyata (mbar)

\subsection{Kebutuhan air konsumtif}

Kebutuhan air konsumtif diartikan sebagai keperluan air bagi tanaman di lahan. Dalam hal ini dipengaruhi faktor koefisien tanaman $(\mathrm{kc})$ dan bersumber dari Kriteria Perencanaan Irigasi-01 (Kementrian Pekerjaan Umum 2003) dan diusulkan oleh FAO untuk koefisien tanaman padi dan koefisien tanaman palawija. Persamaan umum yang digunakan yaitu:

$$
E t c=\text { Eto } x k c
$$

dengan:

Etc $=$ kebutuhan air konsumtif $(\mathrm{mm} /$ hari $)$

Eto $=$ evapotranspirasi $(\mathrm{mm} / \mathrm{hari})$

$\mathrm{kc}=$ koefisien tanaman

\subsection{Kebutuhan air penyiapan lahan}

Faktor kebutuhan air untuk penyiapan lahan antara lain waktu yang dibutuhkan untuk penyiapan lahan $(\mathrm{T})$ dan lapisan air yang dibutuhkan untuk penjenuhan lahan (S) (Kementrian Pekerjaan Umum 2003), yaitu:

$$
I R=M\left(\frac{e^{k}}{e^{k}-1}\right)
$$

dengan:

$\mathrm{IR}=$ kebutuhan air penyiapan lahan $(\mathrm{mm} / \mathrm{hari})$

$\mathrm{M}=(\mathrm{Eo}+\mathrm{P})(\mathrm{mm} / \mathrm{hari})$

$\mathrm{P}=\operatorname{perkolasi}(\mathrm{mm} / \mathrm{hari})$

Eo $=$ evaporasi air terbuka $(=1.1 \times$ Eto $)(\mathrm{mm} / \mathrm{hari})$

$\mathrm{k}=\mathrm{M}(\mathrm{T} / \mathrm{S})$

$\mathrm{e} \quad=$ koefisien

$\mathrm{S}=$ kebutuhan air penjenuhan 200 (tanah lempung) ditambah lapisan air $50((\mathrm{~mm} / \mathrm{hari})$

\subsection{Kebutuhan air untuk mengganti lapisan air (WLR)}

Kebutuhan air untuk mengganti lapisan air adalah besarnya kebutuhan air untuk mengganti lapisan air yaitu sebesar $50 \mathrm{~mm} /$ hari selama sebulan atau $3.3 \mathrm{~mm} /$ hari selama $1 / 2$ bulan dan dua bulan setelah transplantasi (Kementrian Pekerjaan Umum 2003).

\subsection{Perkolasi}

Laju perkolasi sangat terpaut pada sifat tanah yang pada umumnya terpaut pada kegiatan pemanfaatan lahan atau pengolahan tanah antara $2-3 \mathrm{~mm} /$ hari untuk tanah lempung.

\subsection{Curah hujan efektif}

Curah hujan efektif adalah curah hujan andalan yang jatuh pada suatu tempat yang memiliki fungsi sebagai pertumbuhan tanaman. Besar nilai curah hujan efektif untuk tanaman padi diambil $80 \%$ dari curah hujan andalan 15 harian dengan periode ulang rencana tertentu dengan persamaan sebagai berikut (Kementrian Pekerjaan Umum 2003): 


$$
R e=0.7 \times \frac{R 80}{15}
$$

dengan:

$\mathrm{Re}=$ curah hujan efektif ( $\mathrm{mm} /$ hari)

$\mathrm{R}_{80}=$ hujan andalan dengan probabilitas $80 \%(\mathrm{~mm})$

Sedangkan curah hujan efektif palawija didapat dengan periode tertentu dan dihubungkan dengan curah hujan andalan 15 harian terpenuhi 50\% $\left(\mathrm{R}_{50}\right)$ (Kementrian Pekerjaan Umum 2003).

\subsection{Efisiensi irigasi}

Efisiensi irigasi merupakan faktor yang paling utama dari kerja suatu sistem jaringan irigasi. Efisiensi irigasi terdiri atas efisiensi pengaliran di jaringan utama dan efisiensi di jaringan sekunder (Kementrian Pekerjaan Umum 2003). Efisiensi irigasi berasumsi bahwa sebagian jumlah air yang diambil akan hilang baik di saluran maupun di petak sawah. Kehilangan air disebabkan oleh kegiatan eksploitasi, evaporasi dan rembesan. Efisiensi irigasi yang digunakan yaitu $65 \%$.

\subsection{Kebutuhan air baku}

Untuk mendapatkan rencana jumlah kebutuhan air baku terlebih dahulu harus didapat jumlah penduduk yang ada pada saat ini serta proyeksi jumlah penduduk pada periode mendatang. Perhitungan proyeksi jumlah penduduk dapat menggunakan metode:

- Metode Aritmatik

$$
\begin{aligned}
& P_{n}=P_{0}+K_{a}\left(T_{n}-T_{0}\right) \\
& K_{a}=\frac{P_{2}-P_{1}}{P_{1}}
\end{aligned}
$$

dengan:

$\mathrm{P}_{\mathrm{n}}=$ jumlah penduduk pada tahun ke $\mathrm{n}$

$\mathrm{P}_{0}=$ jumlah penduduk pada tahun dasar

$\mathrm{T}_{\mathrm{n}}=$ tahun ke $\mathrm{n}$

$\mathrm{T}_{0}=$ tahun dasar

$\mathrm{K}_{\mathrm{a}}=$ konstanta aritmatik

$\mathrm{P}_{1}=$ jumlah penduduk pada tahun $\mathrm{I}$

$\mathrm{P}_{2}=$ jumlah penduduk pada tahun II

- Metode Geometrik

$$
P_{n}=(1+r)^{n}
$$

dengan:

$\mathrm{r}=$ laju pertumbuhan penduduk per tahun

$\mathrm{n}=$ jumlah interval tahun

- Metode Eksponensial

$$
P_{n}=P_{0} e^{(r n)}
$$

dengan:

$e=$ bilangan pokok logaritma natural adalah 2.718

Cara mendapatkan hasil proyeksi penduduk yang digunakan sebagai patokan perencanaan yaitu dengan menggunakan satu metode yang paling mencerminkan pola pertumbuhan penduduk di wilayah perencanaan. Standar deviasi diartikan sebagai nilai atau standar yang memperlihatkan besar jarak nilai rata-rata. Jadi semakin tinggi nilai standar deviasi, maka data semakin tidak akurat. Berikut ini rumus dari perhitungan standar deviasi

$$
\mathrm{S}=\sqrt{\frac{\sum_{\mathrm{i}}^{\mathrm{n}}=\left(\mathrm{x}_{1}-\underline{\mathrm{x}}\right)}{\mathrm{n}}}
$$


dengan:

$\mathrm{S}=$ standar deviasi

$\mathrm{X}_{\mathrm{i}}=$ nilai varian (proyeksi penduduk)

$\mathrm{n}=$ jumlah data

$\underline{X}=$ nilai rata-rata

\subsection{Kebutuhan air baku domestik}

Berdasarkan buku pedoman penentuan kebutuhan air baku untuk rumah tangga, perkotaan dan industri, kebutuhan air rumah tangga (domestik) dicari menggunakan cara (Departemen Permukiman dan Prasarana Wilayah 2012):

$$
Q=q x \frac{P}{(24 \times 60 \times 60)}
$$

dengan:

$\mathrm{Q}=$ kebutuhan air bersih (liter/detik)

$\mathrm{q}=$ standar kebutuhan air (jiwa/liter/hari)

$\mathrm{P}=$ jumlah penduduk (jiwa)

\subsection{Kebutuhan air baku non domestik dan industri}

Standar kebutuhan air untuk perkotaan, antara lain seperti fasilitas komersial (hotel), fasilitas kesehatan (rumah sakit dan puskesmas), fasilitas pariwisata, dan fasilitas pendidikan (non domestik) sebesar 25\% dari kebutuhan air domestik, sedangkan kebutuhan air untuk Industri diperkiraan sebesar 15\% dari kebutuhan air domestik (Departemen Permukiman dan Prasarana Wilayah 2012).

\subsection{Kehilangan air sebagai evaporasi}

Evaporasi merupakan suatu proses perubahan fisik yang tadinya berbentuk cair atau padat berubah menjadi gas akibat adanya perpindahan panas. Faktor yang mempengaruhi evaporasi yaitu faktor klimatologi setempat. Evaporasi pada analisis ini menggunakan metode Transfer Massa seperti berikut:

$$
E=0.35\left(0.5+0.54 U_{2}\right)(e a-e d)
$$

dengan:

$\mathrm{E}=$ evaporasi (mm/hari)
$\mathrm{U}_{2}=\operatorname{kecepatan}$ angin $(\mathrm{m} /$ detik)
$\mathrm{ea}=$ tekanan uap jenuh $(\mathrm{mm} \mathrm{Hg})$
$\mathrm{ed}=$ tekanan uap udara $(\mathrm{mm} \mathrm{Hg})$

\subsection{Pola dan simulasi operasi waduk}

Pola operasi waduk adalah patokan operasional periode suatu waduk di mana debit air yang dihasilkan harus mengikuti ketentuan untuk menjaga elevasi waduk sesuai dengan rancangan. Sesuai dengan tujuan utama pembangunan Waduk Tamblang adalah untuk menampung, mengendalikan dan memanfaatkan potensi air di Tukad Daya baik di musim kemarau maupun di musim penghujan. Untuk mencapai sasaran tersebut maka perlunya simulasi operasi waduk sangat penting dikarenakan agar waduk dapat beroperasi dengan baik untuk memenuhi kebutuhan air irigasi dan air baku di Kecamatan Sawan dan Kecamatan Kubutambahan Kabupaten Buleleng Provinsi Bali. Dalam simulasi perilaku operasi suatu waduk berfungsi untuk mendapati perubahan kekuatan tampungan waduk. Persamaan simulasi yang dapat digunakan yaitu:

$$
S_{t}=S_{t-1}+Q_{t}-E_{t}-D_{t}
$$

dengan:

$\mathrm{S}_{\mathrm{t}}=$ volume reservoir pada bulan ke $\mathrm{n}$

$\mathrm{S}_{\mathrm{t}-1}=$ volume reservoir sebelum bulan ke $\mathrm{n}$

$\mathrm{Q}_{\mathrm{t}}=$ inflow (debit andalan + curah hujan andalan selama bulan ke $\mathrm{n}$ )

$\mathrm{E}_{\mathrm{t}}=$ evaporasi pada bulan ke $\mathrm{n}$ 
$\mathrm{D}_{\mathrm{t}}=$ outflow (kebutuhan air irigasi + kebutuhan air baku selama bulan ke $\mathrm{n}$ )

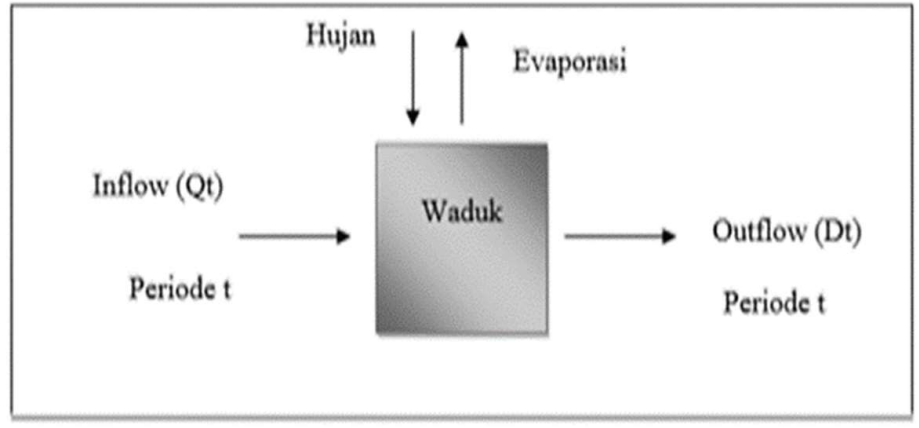

Gambar 1. Model pola dan simulasi operasi waduk

\subsection{Metode penelitian}

Waduk Tamblang berlokasi pada aliran Tukad Daya yang secara administratif berada di dua desa yaitu Desa Sawan Kecamatan Sawan dan Desa Bila Kecamatan Kubutambahan Kabupaten Buleleng. Pengumpulan data dalam penelitian ini didapat dari kantor Dinas/Instansi yang terkait yaitu, Kantor Balai Wilayah Sungai Bali-Penida, dan Badan Pusat Statistik Kabupaten Buleleng. Data-data tersebut antara lain:

- Data teknis Waduk Tamblang didapat dari Kantor Balai Wilayah Sungai Bali-Penida.

- Data curah hujan Stasiun Sawan didapat dari Kantor Balai Wilayah Sungai Bali-Penida.

- Data debit Sungai Daya didapat dari Kantor Balai Wilayah Sungai Bali-Penida.

- Data klimatologi di Kabupaten Buleleng tahun 2016 didapat dari Kantor Balai Wilayah Sungai Bali-Penida.

- Data jumlah penduduk Kecamatan Sawan dan Kecamatan Kubutambahan didapat dari Badan Pusat Statistik Kabupaten Buleleng.

- Data luas area dan skema irigasi didapat dari Kantor Balai Wilayah Sungai Penida.

\section{Hasil dan Pembahasan}

\subsection{Data teknis waduk tamblang}

Data teknis Waduk Tamblang diperlukan guna menunjang dalam menganalisis pola operasi waduk (Balai Wilayah Sungai Bali Penida 2018), yaitu:

- Luas waduk : $394,641 \mathrm{~m}^{2}$

- Luas daerah genangan : $355,418 \mathrm{~m}^{2}$

- Volume bruto (total) : $6,137,228 \mathrm{~m}^{3}$

- Volume efektif : 4,199,646 $\mathrm{m}^{3}$

- Volume mati : $1,937,583 \mathrm{~m}^{3}$

- Elevasi muka air tertinggi (FWL) : : $+183.80 \mathrm{~m}$

- Elevasi muka air normal (NWL) : : $+179.50 \mathrm{~m}$

- Elevasi muka air terendah (LWL) : : $+161.00 \mathrm{~m}$

\subsection{Analisis debit andalan}

Perhitungan debit andalan DAS Tukad Daya diperoleh dari data debit harian Tukad Daya dalam satuan ( $\mathrm{m}^{3} /$ detik) tahun 2008-2016 yang dirata-rata 15 harian (Balai Wilayah Sungai Bali Penida 2018), selanjutnya di rangking dari besar ke kecil setelah itu diploting dengan metode Weibull, dan kemudian digunakan probabilitas $90 \%\left(\mathrm{R}_{90}\right)$ dan probabilitas $80 \%\left(\mathrm{R}_{80}\right)($ Gambar 2$)$. 


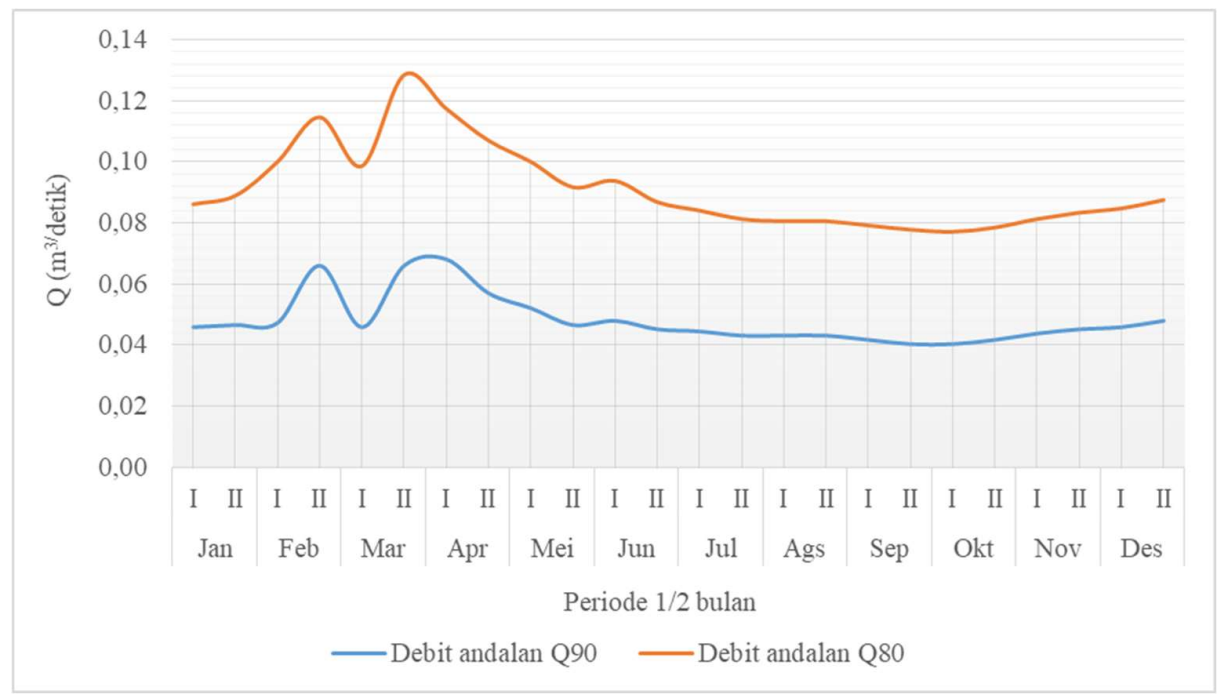

Gambar 2. Debit andalan sebagai inflow Waduk Tamblang

\subsection{Analisis curah hujan andalan}

Perhitungan hujan andalan DAS Tukad Daya diperoleh dari data hujan harian Stasiun Sawan dalam satuan (mm) pada Tukad Daya tahun 2008-2016 yang dijumlah 15 harian (Balai Wilayah Sungai Bali Penida 2018), selanjutnya di rangking dari besar ke kecil setelah itu diploting dengan metode Weibull, dan kemudian digunakan probabilitas $90 \%\left(\mathrm{R}_{90}\right), 50 \%\left(\mathrm{R}_{50}\right)$, dan probabilitas $80 \%$ $\left(\mathrm{R}_{80}\right)$ (Gambar 3).

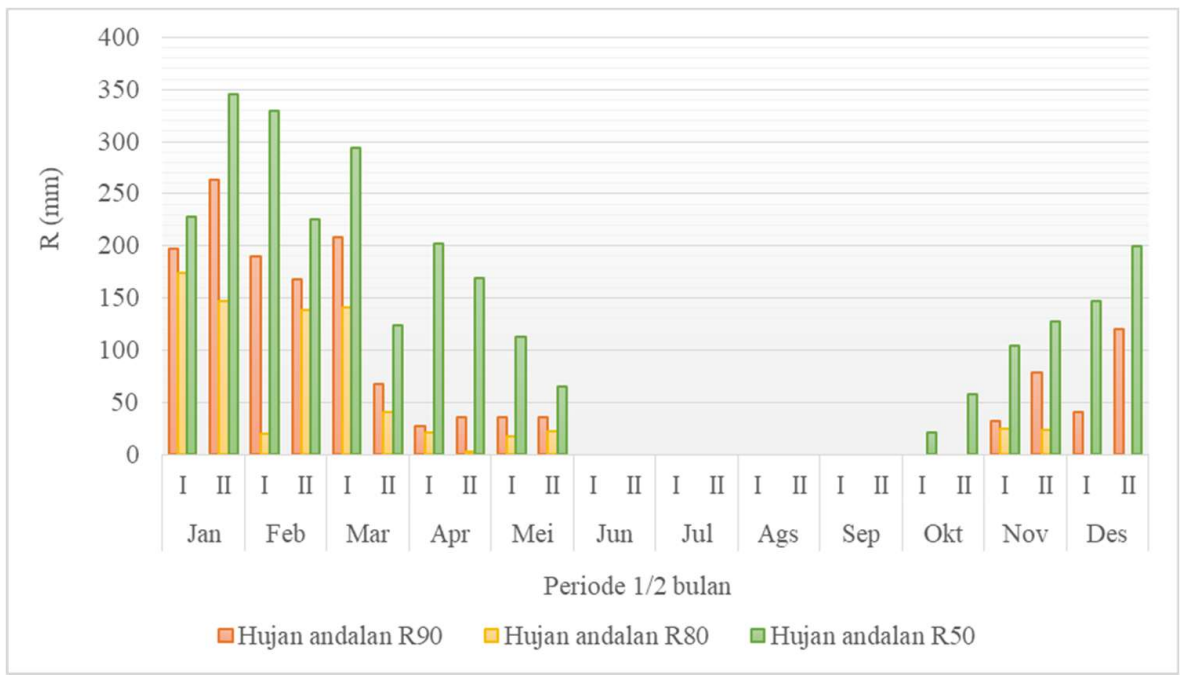

Gambar 3. Curah hujan andalan

\subsection{Analisis curah hujan efektif}

Curah hujan efektif adalah curah hujan andalan yang jatuh pada suatu tempat yang memiliki fungsi sebagai pertumbuhan tanaman. Besar nilai curah hujan efektif yang digunakan untuk tanaman padi diambil $80 \%$ dari curah hujan andalan 15 harian dengan periode ulang rencana tertentu. Curah hujan efektif palawija menurut Kriteria Perencanaan Irigasi-01 (Kementrian Pekerjaan Umum 2003), didapat dengan periode tertentu dan dihubungkan dengan curah hujan andalan 15 harian terpenuhi $50 \%\left(\mathrm{R}_{50}\right)($ Gambar 4$)$. 


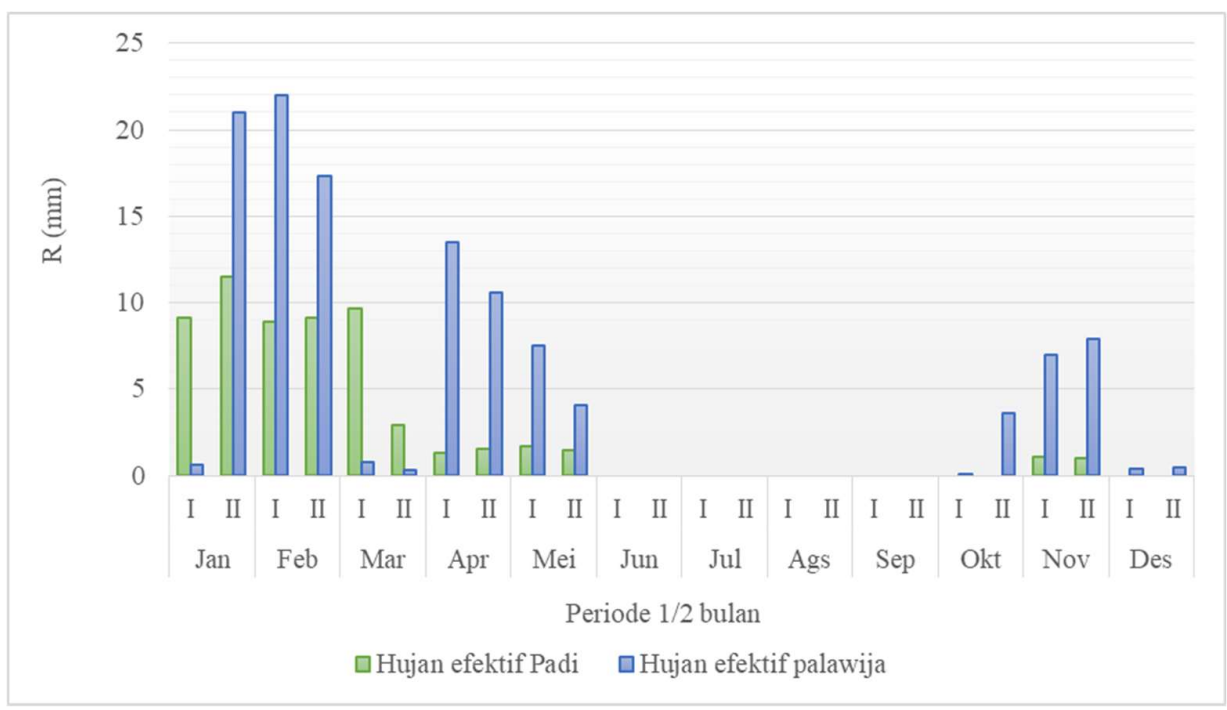

Gambar 4. Curah hujan efektif untuk kebutuhan air tanaman

\subsection{Analisis evapotranspirasi potensial}

Evapotranspirasi potensial didapatkan dengan menggunakan metode Penman Modifikasi oleh FAO. Besarnya evapotranspirasi potensial menggunakan rumus teoritis sesuai pada metode yang dikeluarkan oleh FAO dengan menggunakan faktor-faktor klimatologi daerah Singaraja pada tahun 2016 yang didapatkan dari Balai Wilayah Sungai Bali Penida (Tabel 1).

Tabel 1. Evapotranspirasi potensial

\begin{tabular}{cc}
\hline \multicolumn{2}{c}{ Rekapan Hasil Evapotranspirasi } \\
\hline Bulan & Eto (mm/hari) \\
\hline Januari & 4.57 \\
\hline Februari & 4.59 \\
\hline Maret & 5.29 \\
\hline April & 4.58 \\
\hline Mei & 4.34 \\
\hline Juni & 4.06 \\
\hline Juli & 4.16 \\
\hline Agustus & 4.71 \\
\hline September & 5.04 \\
\hline Oktober & 5.27 \\
\hline November & 4.89 \\
\hline Desember & 4.36 \\
\hline
\end{tabular}

\subsection{Analisis kebutuhan air irigasi}

Kebutuhan air irigasi analisis ini akan memberikan manfaat untuk dua daerah irigasi yaitu DI Bungkulan dan DI Bulian Kabupaten Buleleng dengan luas 584 ha. Faktor-faktor yang dapat mempengaruhi kebutuhan air irigasi adalah klimatologi, kondisi tanah, koefisien tanaman, pola tanam, pasokan air, luar daerah irigasi, efisiensi irigasi, penggunaan kembali air drainase untuk irigasi, sistem golongan, jadwal tanam dan lain sebagainya. Kebutuhan air irigasi dalam analisis ini menggunakan lima alternatif pola tata tanam dengan dua alternatif yang tidak terjadi kekurangan air pada proses simulasi waduk yaitu alternatif 4 dan alternatif 5 (Gambar 5). 


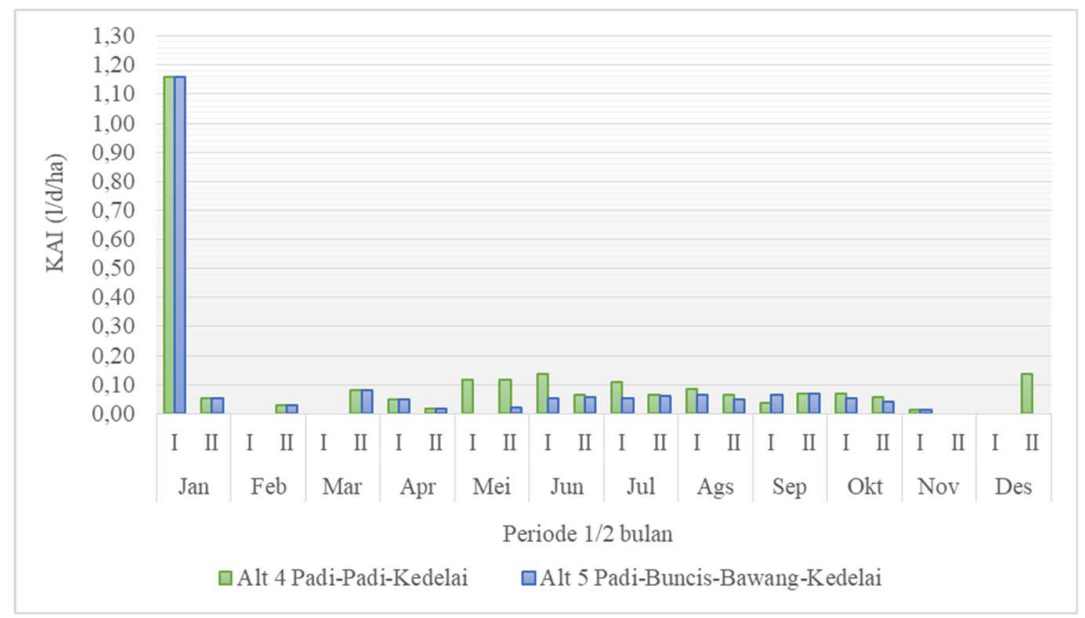

Gambar 5. Kebutuhan air irigasi alternatif 4 dan 5

\subsection{Analisis kebutuhan air baku}

Kebutuhan air baku pada analisis ini dibagi menjadi tiga yaitu air baku domestik, non domestik dan industri. Kebutuhan air baku direncanakan hingga tahun 2040 untuk melayani Kecamatan Sawan dan Kubutambahan Kabupaten Buleleng. Perhitungan proyeksi penduduk menggunakan tiga metode seperti pada metode dengan menggunakan tahun dasar jumlah penduduk yang diketahui pada tahun 2011 dan 2012 yang didapat dari Balai Wilayah Sungai Bali Penida. Laju pertumbuhan penduduk didapat dari analisis yaitu $1.42 \%$ pada Kecamatan Kubutambahan dan $0.27 \%$ pada Kecamatan Sawan Kabupaten Buleleng. Analisis dari ke tiga metode proyeksi tersebut didapatkan hasil melalui standar deviasi Metode Aritmatik yang paling mendekati akurat, sehingga untuk memperhitungkan kebutuhan air baku pada analisis ini digunakan Metode Aritmatik sebagai acuan dalam proyeksi penduduk dengan hasil rekapan kebutuhan total air baku pada Kecamatan Sawan dan Kubutambahan diperoleh kebutuhan terbesar mencapai 205.72 liter/detik pada tahun 2040 untuk 141,062 orang penduduk, sehingga diambil jumlah tersebut yang dipakai acuan pada simulasi operasi waduk.

\subsection{Analisis evaporasi}

Untuk menentukan besarnya kehilangan air di waduk karena evaporasi dalam studi ini pendekatan yang digunakan adalah metode Transfer Massa. Faktor-faktor klimatologi dalam analisis evaporasi ini bersumber dari data klimatologi Singaraja tahun 2016 (Balai Wilayah Sungai Bali Penida 2018). Analisis evaporasi dengan metode Transfer Massa dapat dilihat pada Tabel 2.

Tabel 2. Evaporasi air terbuka

\begin{tabular}{cc}
\hline \multicolumn{2}{c}{ Rekapan Hasil Evaporasi Transfer Massa } \\
\hline Bulan & Eto (mm/hari) \\
\hline Januari & 1.61 \\
\hline Februari & 1.57 \\
\hline Maret & 2.94 \\
\hline April & 1.51 \\
\hline Mei & 1.71 \\
\hline Juni & 1.61 \\
\hline Juli & 1.72 \\
\hline Agustus & 1.90 \\
\hline September & 1.79 \\
\hline Oktober & 1.66 \\
\hline November & 1.62 \\
\hline Desember & 1.25 \\
\hline
\end{tabular}




\subsection{Analisis pola operasi waduk}

Simulasi operasi waduk adalah patokan operasional periode suatu waduk yang mana debit air masuk terdapat dalam waduk harus mencukupi kebutuhan air rencana waduk untuk menjaga elevasi waduk sesuai dengan rancangan (Yekti et al. 2020). Analisis simulasi Waduk Tamblang dilakukan dengan menggunakan lima alternatif pola tata tanam pada dua jenis keandalan debit inflow dan hasilnya seperti Tabel 3.

Tabel 3. Rekapitulasi keandalan operasi waduk tamblang

\begin{tabular}{|c|c|c|c|c|}
\hline Pola Operasi Waduk & $\begin{array}{l}\text { Periode } \\
\text { simulasi }\end{array}$ & Sukses & Gagal & $\begin{array}{c}\text { Keandalan } \\
\text { Waduk (\%) }\end{array}$ \\
\hline Alternatif $1 \mathrm{Q}_{80}$ PTT 1 & 24 & 16 & 8 & 66.70 \\
\hline Alternatif $2 \mathrm{Q}_{80}$ PTT 2 & 24 & 19 & 5 & 79.20 \\
\hline Alternatif $3 \mathrm{Q}_{80}$ PTT 3 & 24 & 21 & 3 & 87.05 \\
\hline Alternatif $4 \mathrm{Q}_{80}$ PTT 4 & 24 & 24 & 0 & 100.00 \\
\hline Alternatif $5 \mathrm{Q}_{80}$ PTT 5 & 24 & 24 & 0 & 100.00 \\
\hline Alternatif $1 \mathrm{Q}_{90}$ PTT 1 & 24 & 15 & 9 & 62.05 \\
\hline Alternatif $2 \mathrm{Q}_{90}$ PTT 2 & 24 & 18 & 6 & 75.00 \\
\hline Alternatif $3 \mathrm{Q}_{90}$ PTT 3 & 24 & 21 & 3 & 87.05 \\
\hline Alternatif $4 \mathrm{Q}_{90}$ PTT 4 & 24 & 24 & 0 & 100.00 \\
\hline Alternatif $5 \mathrm{Q}_{90}$ PTT 5 & 24 & 24 & 0 & 100.00 \\
\hline
\end{tabular}

Ketersediaan air pada Waduk Tamblang berdasarkan debit andalan $80 \%$ di dapatkan debit tertinggi 1,464,617 $\mathrm{m}^{3}$ yang terjadi pada Bulan Februari (15 hari pertama), sementara debit terendah $755,136 \mathrm{~m}^{3}$ terjadi pada Bulan September (15 hari kedua). Ketersediaan air pada Waduk Tamblang berdasarkan debit andalan $90 \%$ didapatkan volume tertinggi 1,262,188 $\mathrm{m}^{3}$ yang terjadi pada Bulan Maret (15 hari kedua), sementara volume terendah $691,200 \mathrm{~m}^{3}$ terjadi pada Bulan Oktober (15 hari pertama).

Kebutuhan air irigasi, air baku, dan evaporasi sebagai outflow pada Waduk Tamblang berdasarkan total outflow pada beberapa simulasi operasi waduk di dapatkan outflow tertinggi pada simulasi pertama 2,531,305 $\mathrm{m}^{3}$ yang terjadi pada Bulan Desember (15 hari kedua), sementara outflow terendah 273,261 $\mathrm{m}^{3}$ terjadi pada Bulan Desember (15 hari pertama), pada simulasi kedua di dapatkan outflow tertinggi 2,629,456 $\mathrm{m}^{3}$ yang terjadi pada Bulan Oktober (15 hari kedua), sementara outflow terendah $275,175 \mathrm{~m}^{3}$ terjadi pada Bulan Januari (15 hari pertama), pada simulasi ketiga di dapatkan outflow tertinggi 2,629,456 $\mathrm{m}^{3}$ yang terjadi pada Bulan Oktober (15 hari kedua), sementara outflow terendah $275,175 \mathrm{~m}^{3}$ terjadi pada Bulan Januari (15 hari pertama), pada simulasi keempat di dapatkan outflow tertinggi 1,583,905 $\mathrm{m}^{3}$ yang terjadi pada Bulan Maret (15 hari kedua), sementara outflow terendah 273,261 $\mathrm{m}^{3}$ terjadi pada Bulan Desember (15 hari pertama), dan pada simulasi kelima di dapatkan outflow tertinggi 1,583,905 $\mathrm{m}^{3}$ yang terjadi pada Bulan Maret (15 hari kedua), sementara outflow terendah 273,261 $\mathrm{m}^{3}$ terjadi pada Bulan Desember (15 hari pertama).

Berdasarkan analisis rekap hasil simulasi operasi rencana Waduk Tamblang didapat hasil bahwa dalam kurun waktu 1 tahun operasi waduk dengan debit inflow $\mathrm{Q}_{80}$ dan $\mathrm{Q}_{90}$ alternatif 1 sampai 3 terjadi defisit (kekurangan air) melainkan alternatif 4 dan 5 sudah tidak terjadi defisit (kekurangan air). Simulasi operasi Waduk Tamblang dengan debit andalan $80 \%$ dan $90 \%$ alternatif 1 menggunakan pola tata tanam padi-padi-palawija (kedelai), alternatif 2 menggunakan pola tata tanam padi-padi-palawija (jagung), alternatif 3 menggunakan pola tata tanam padi-padi, alternatif 4 menggunakan pola tata tanam padi-palawija (jagung)-palawija (kacang tanah), alternatif 5 menggunakan pola tata tanam padi-palawija (buncis)-palawija (bawang)-palawija (kedelai). 


\section{Kesimpulan}

Pola operasi Waduk Tamblang dengan keandalan 100\% (optimum) untuk memenuhi kebutuhan air baku sesuai proyeksi yaitu 205.72 liter/detik dan terpenuhi kebutuhan air irigasi terjadi pada alternatif 4 dan 5 dengan pola tata tanam padi-jagung-kacang tanah dan padi-buncis-bawangkedelai. Disarankan agar berkesinambungan informasi data hujan yang menjadi input waduk, maka diperlukan pos penakar hujan baru dikarenakan hanya ada satu pos penakar hujan dalam catchment area Waduk Tamblang. Disarankan untuk keandalan operasi Waduk Tamblang mencapai 100\% agar menggunakan alternatif pola tata tanam dengan model pola tata tanam padi-palawija-palawija.

\section{Daftar Pustaka}

Adhiatma, Prayogi, Rini Wahyu Sayekti, and Linda Prasetyorini. 2014. "Studi Pemberian Air Irigasi Berdasarkan Faktor Jarak Sebagai Upaya Pemenuhan Kebutuhan Air Di Daerah Irigasi Kedung Kandang Kabupaten Malang.” Jurnal Ilmiah Jurusan Teknik PengairanTeknik Pengairan Fakultas Teknik Universitas Brawijaya.

Balai Wilayah Sungai Bali Penida. 2018. Laporan Akhir Sertifikasi Desain Bendungan Tamblang Di Kabupaten Buleleng.

Banihabib, Mohammad Ebrahim, and Farzaneh Nazarieh. 2019. "A Model for Simulation of Debris Flow Sedimentation in Slit Detention-Dam Reservoirs." Journal of Hydro-Environment Research 27: 65-74.

Chen, Yi-Feng et al. 2020. "Variation in Hydraulic Conductivity of Fractured Rocks at a Dam Foundation during Operation." Journal of Rock Mechanics and Geotechnical Engineering.

Departemen Permukiman dan Prasarana Wilayah. 2012. Pedoman Penentuan Kebutuhan Air Baku Untuk Rumah Tangga, Perkotaan, Dan Industri.

Kementrian Pekerjaan Umum. 2003. "Standar Perencanaan Irigasi." Kriteria Perencanaan Bagian Jaringan Irigasi KP-O1.

Kuswanto. 2004. "Evaluasi Operasi Waduk Muara Nusa Dua Tahap I Di Kota Denpasar." Teknik Sipil, Fakultas Teknik, Universitas Udayana.

Liu, Changming, and Jun Xia. 2004. "Water Problems and Hydrological Research in the Yellow River and the Huai and Hai River Basins of China." Hydrological Processes 18(12): 2197 2210.

Mahendra, Made Sudiana et al. 2015. Analisis Air Tukad Badung Di Kota Denpasar. Denpasar.

Peraturan Pemerintah Republik Indonesia. 2010. Peraturan Pemerintah Republik Indonesia Nomor 37 Tentang Bendungan.

Triatmodjo, Bambang. 2008. Hidrologi Terapan. Yogyakarta: Beta Offset.

Yaghmaei, Hiva, Seyed Hamidreza Sadeghi, Hamidreza Moradi, and Mehdi Gholamalifard. 2018. "Effect of Dam Operation on Monthly and Annual Trends of Flow Discharge in the Qom Rood Watershed, Iran." Journal of Hydrology 557: 254-64.

Yekti, Mawiti Infantri, I Putu, Dwikarna Putra, and Nyoman Norken. 2020. 22 Agricultural Engineering International: CIGR Journal Alternative Model of Sidan Reservoir Operation for Ayung River Basin Using RIBASIM.

Yekti, Mawiti Infantri, Bart Schultz, Nyoman Norken, and Laszlo Hayde. 2017. 19 Agricultural Engineering International: CIGR Journal Discharge Analysis for a System Approach to River Basin Development with Subak Irrigation Schemes as a Culture Heritage in Bali. 